Research Article

\title{
Hybrid Position/Force Control for Dual-Machine Drilling and Riveting System
}

\author{
Yi Liu (D), Qiang Fang (D, and Yinglin Ke \\ The State Key Lab of Fluid Power Transmission and Control, School of Mechanical Engineering, Zhejiang University, \\ Hangzhou 310000, China \\ Correspondence should be addressed to Qiang Fang; fangqiang@zju.edu.cn
}

Received 26 November 2019; Revised 23 July 2020; Accepted 25 July 2020; Published 24 August 2020

Academic Editor: Stylianos Georgantzinos

Copyright (c) 2020 Yi Liu et al. This is an open access article distributed under the Creative Commons Attribution License, which permits unrestricted use, distribution, and reproduction in any medium, provided the original work is properly cited.

The deformation of riveting machine caused by riveting force during rivet formed makes the riveting tool out of positioning, which leads to gapping underneath the rivet manufactured head and insufficient rivet drive head. This paper proposes a hybrid position/force riveting control method for the dual-machine drilling and riveting system to eliminate the negative effects of machine deformation. The cooperative work of two-side machine tool is realized by a hybrid position/force control strategy, which compensates for the force-induced deformation error without an accurate stiffness model of the riveting system. The position of pressing foot relative to the machine which represents the deformation of skin-side machine is obtained for the compensation to the displacement of skin-side actuator. Simultaneously, the advanced force control is adopted for the stringer-side actuator. The dynamics model of the stringer-side actuator in consideration of the machine deformation is established and identified. The disturbance observer (DOB) and feedforward controller are introduced as the model-based control algorithm to achieve the highperformance force control. Also, contrast experiments are conducted to validate the effectiveness of the proposed riveting control method. The results show that the rivet manufactured head can be seated in the countersink during the forming process and the gapping under the head is eliminated. The driven head height tolerance of $\pm 0.1 \mathrm{~mm}$ is achieved by accurate force control.

\section{Introduction}

Riveting is the main connection form used in aircraft assembly, which can provide enough tension for the aircraft fuselage to withstand the air pressure and other impact. At the same time, the sealing function of riveting is also important in order to meet the aerodynamic requirements. The whole structure of a large aircraft contains as many as 1.5-2 million rivets. Fatigue of riveted joints between aluminum alloy sheets, typical of the pressurized aircraft fuselage, is the major cause of serious security threats [1]. Therefore, improving the riveting quality and the reliability of joints is still the focus and difficulty in the field of aircraft assembly from the aspects of aircraft life and flight safety. Meanwhile, with the development of automation technology, automatic riveting system has been widely used in aviation industry, used to improve the processing quality and production efficiency of aircraft riveting assembly.
Riveting is an assembly method which requires collaborative work on both sides of the panel, and the degree of tacit cooperation is directly related to the processing quality. Therefore, compared with the early artificial riveting, the automatic riveting technology can complete clamping panel, drilling, inserting, and squeezing rivet at one time, which not only improves the production efficiency, but also achieves more stable and higher riveting quality than artificial riveting through the tacit cooperation of equipment. At present, the typical advanced automatic riveting machines are $\mathrm{G}$ series of GEMCOR, E series of EI, and MPAC of BROETJE [2-4].

The quality of riveting is closely related to the driven head size and interference from the analysis of the effect of rivets. A proper driven head can provide sufficient clamping force in the direction of sheet thickness and increase the friction between sheets, which is beneficial to resist the pull from the fuselage pressure. The interference amount 
represents the expansion degree of rivet, and expanded rivets can ensure the sealing of joints. Previous literature also shows that the interference can prevent the generation of fatigue crack and prolong the fatigue life of riveted joints [5]. The driven head size and the interference can reflect the amount of force needed during rivets formed because a larger riveting force can obtain a larger diameter of driven head and the amount of expansion [6, 7].

The machine tool errors mainly include geometric error, deformation error, and thermal error. Generally, the thermal error is the main source for the cutting machine tool while the deformation error is the minimum one [8]. Different from the conventional machine tools, the force applied by the automatic riveting machine can reach several tons during the rivet formed, so the counterforce of the riveting force acting on the machine causes machine deformation, which becomes the main error of riveting machine. The force-induced deformation has an adverse effect on both sides of the riveted sheets. On the stringer side, the deformation error will lead to insufficient riveting and the driven head size cannot reach the preset value. On the skin side, the machine tool will not completely resist the rivet manufactured head and it will show insufficient contact between the rivet head and the countersink, which cannot meet the requirements of sealing and shape aerodynamics. Meanwhile, some of the deformation error will also be transferred to the driven head size error. The rivet has little additional material on the manufactured head, which means that very few materials can flow into the countersink during squeezing the rivet and create an interference with the countersink hole around the head. As a consequence, the gapping underneath the rivet manufactured head is the most common issue during riveting process. Because of the lack of material flow, it is necessary to ensure that the rivet manufactured head cannot be extruded out of the countersink during the rivet formed in order to avoid the gapping. However, since the stiffness of automatic riveting machine is limited, it is impossible to guarantee the rivet to contact with the countersink without any compensation for eliminating unwanted motion of manufactured head, which could create gapping under the head.

In order to compensate the deformation error of machine tools, the previous literature has done lots of research on the identification of machine tool stiffness model, including analytical modeling, finite element simulation, and experimental measurement. Wang [9] designed an optimal CNC machine structure through the proposed integrative examination of two structural parameters and the CAE technique, and the newly designed structure shows a great improvement in the maximal deformation of the machine structure under the action of cutting forces. Huang et al. [10] studied a hybrid module finite element modeling for analyzing the stiffness of machine tools. Smaoui et al. [11] realized the simulation of tool deflection trajectory based on cutting force by using finite element method and experiments. They corrected the trajectory through this method to correct and compensate the errors caused by tool deflection.

In terms of compensation for force-induced deformation error of automatic riveting machine, Zieve et al. [12] proposed a suppression method for the deformation of the panel caused by riveting process; the solution to this problem is by forming the rivet with the pressure foot extended. This compensation method has proven to be effective but the extended value is obtained by the trial and error method, which is lack of adaptability to rivets of different sizes. Liu et al. [13] developed a prediction and compensation method of force-induced deformation based on finite element modeling and artificial neural network, and the motion commands are modified to compensate for the predicted error. The constant experiment verifies the feasibility of this method, but the disadvantage of this method cannot obtain the complete deformation data under all the possible machine postures. Zhang et al. [14] put forward an efficient online compensation method for the stress and deformation on automatic riveting machine based on the analysis of force-displacement data during the riveting process. These methods have been proved to be used in the machine tool error compensation, but when the layout of the automatic riveting system is complex, whose stiffness varies with the shape of different products in the machining space, the traditional modeling and identification methods will be limited. The workload of modeling and measuring the forcedeformation data of machine tool in machining space is quite huge, and it is difficult to guarantee the accuracy of stiffness model. As mentioned earlier, the desired driven head size can be obtained by controlling the riveting force, so an efficient and accurate force control system is rational and feasible to indirectly compensate the force-induced machine deformation error without additional compensation model since it is difficult to accurately be established.

Recently, the hybrid position/force control scheme is widely introduced to improve the interactive performance of human-machine or machine-environment. Duan et al. [15] presented an adaptive variable impedance control to improve the contact force accuracy between the robot and environment, which can adapt the environment stiffness uncertainties. Peng et al. [16] proposed an adaptive Jacobian and network based position/force tracking impedance control method to achieve precise force control performance indirectly by using the position tracking. Zhang et al. [17] proposed a disturbance observer-based hybrid sliding mode impedance control method to achieve robot end constant contact force tracking control, and the disturbance observer can estimate the robot end contact force to improve the control precision. Gan et al. [18] discussed the trajectory planning and position/force coordination control of multirobot systems during the welding process, and the proposed symmetrical internal and external adaptive variable impedance control for position/force tracking of multirobot cooperative manipulators can realize the tracking of a dynamic desired force and compensation for the unknown trajectory deviations. Since the tracking performance and the robustness of the hybrid control system are important, the force control should be designed considering the system characteristics. However, the riveting die will retreat during the rivet formed, so its transmission shaft reflects the flexibility, which will limit the performance of force control. The riveting die transmission shaft should be considered as a 
flexible shaft in order to improve the efficiency and accuracy of force control. In the research of force control of flexible shaft, disturbance observer and feedforward control based on system dynamics are the most effective control strategies to improve the robustness and dynamic performance of the system. Liu et al. [19] proposed a disturbance observer optimization design method based on iterative feedback of first-order delay model and solved the optimization problem of the nominal model. Yun et al. [20] proposed a design method of Q filter in DOB and achieved the optimal performance of disturbance attenuation through loop shaping. Wang et al. [21] designed two disturbance observers to cope with the stable motion state and high disturbance state of the system and proposed a switching method based on output error and stable time to achieve different control performance by switching between the two DOB systems. Oh et al. [22] adopted DOB and feedforward control for a series elastic actuator mechanism to improve the robustness and dynamic performance of the force control. The accuracy of system dynamics modeling determines the performance of DOB and feedforward controller.

Considering the impossibility of establishing a complete force-induced deformation error compensation model for the dual-machine riveting system, the hybrid position/force controller is proposed in this paper, where the deformation error can be compensated indirectly through the precise force control and the cooperation of dual-machine system is realized by the position compensation control. Consequently, the main contribution of this paper is presented as follows:

(1) A dual-machine riveting system is presented in this paper, and the hybrid position/force control scheme is proposed to solve the force-induced deformation error compensation for the unique dual-machine layout

(2) The high-performance force control of the riveting system can be achieved utilizing the system dynamic model, and the model-based control algorithm of DOB and feedforward can be successfully applied to the riveting force control

(3) The outer-loop position compensation control based on the special design of the pressure foot can solve the cooperation of dual-machine

(4) The filter design in the proposed hybrid position/ force control method is important to suppress the external disturbances, measurement noise, and modeling uncertainty

The remainder of this paper is organized as follows. Firstly, the deformation characteristics of the dual-machine riveting system are analyzed, and the hybrid position/force control strategy is proposed to realize the cooperative work of the riveting dies on both sides. Secondly, the position signal of the pressuring foot to the base of riveting actuator is added in the position control loop of skin-side die to realize the online compensation of the machine deformation, so that the unwanted motion of the rivet manufactured head is eliminated, which could create gapping under the head.
Then, the dynamics of the riveting actuator is established and the stiffness in the model is measured. The feedforward controller and DOB are designed based on the established and identified nominal model. Finally, the riveting control method is validated on the dual-machine riveting system, and the contribution of the proposed method is summarized.

\section{System Model}

2.1. System Structure. Traditional automatic drilling and riveting machines adopt close structure to bear the huge riveting force during squeezing the rivet, such as C-frame, $\mathrm{D}$-frame, or gantry. The machine deformation is relatively small and the riveting die can compensate for the deflection in the axis drivetrain using linear calibration. Meanwhile, the disadvantages of these layouts are also obvious: the "offground" mode will extend the riveting assembly cycle because the artificially preconnected panels should be replaced with the special fixture of the riveting machine. The efficiency of the assembly line is restricted by the refixture of panels. This paper presents a dual-machine horizontal drilling and riveting system as shown in Figure 1. This riveting system adopts two independent five-axis motion mechanisms, and the alignment of actuators is collinear by collaborative calibration and CNC control without mechanical connection $[23,24]$. Compared with previous riveting machines, the open layout can provide a general, high-quality, and low-cost automatic riveting operation solution for aircraft panels, greatly improving the efficiency [25].

Dual-machine riveting system consists of two separate collaborative five-axis machine tools: the drilling-inserting machine and the riveting machine. Because the machines are distributed on the inside and outside of the panel, the machine on the skin side for drilling and inserting rivets is defined as the outside machine, and the machine on the stringer/frame side for squeezing rivets is defined as the inside machine. In this system, the outside machine moves to the riveted position of panel as the positioning active machine, and the inside machine moves with the outside machine as the passive machine tool. Both machines contain five axes: three translation axes $X, Y, Z$ and two rotation axes A, B.

The panel is transported to the middle of the two machines by the automated guided vehicle, and the position of the panel is recognized in the machine coordinate system using the visual measurement system of the outside machine, which can acquire the position data of reference points on the fixture and compare with their theoretical value. Based on the fast recognition of panels, the dualmachine riveting system has strong flexibility, which can be used for riveting of various sizes of panels. Moreover, the panel is easy to access without obstacles so it is more convenient for the daily maintenance of machine. The independent movement and cooperative operation of the two machines have the advantages of high flexibility and high adaptability, but the dual-machine layout leads to the relatively weak rigidity of the machine compared with 

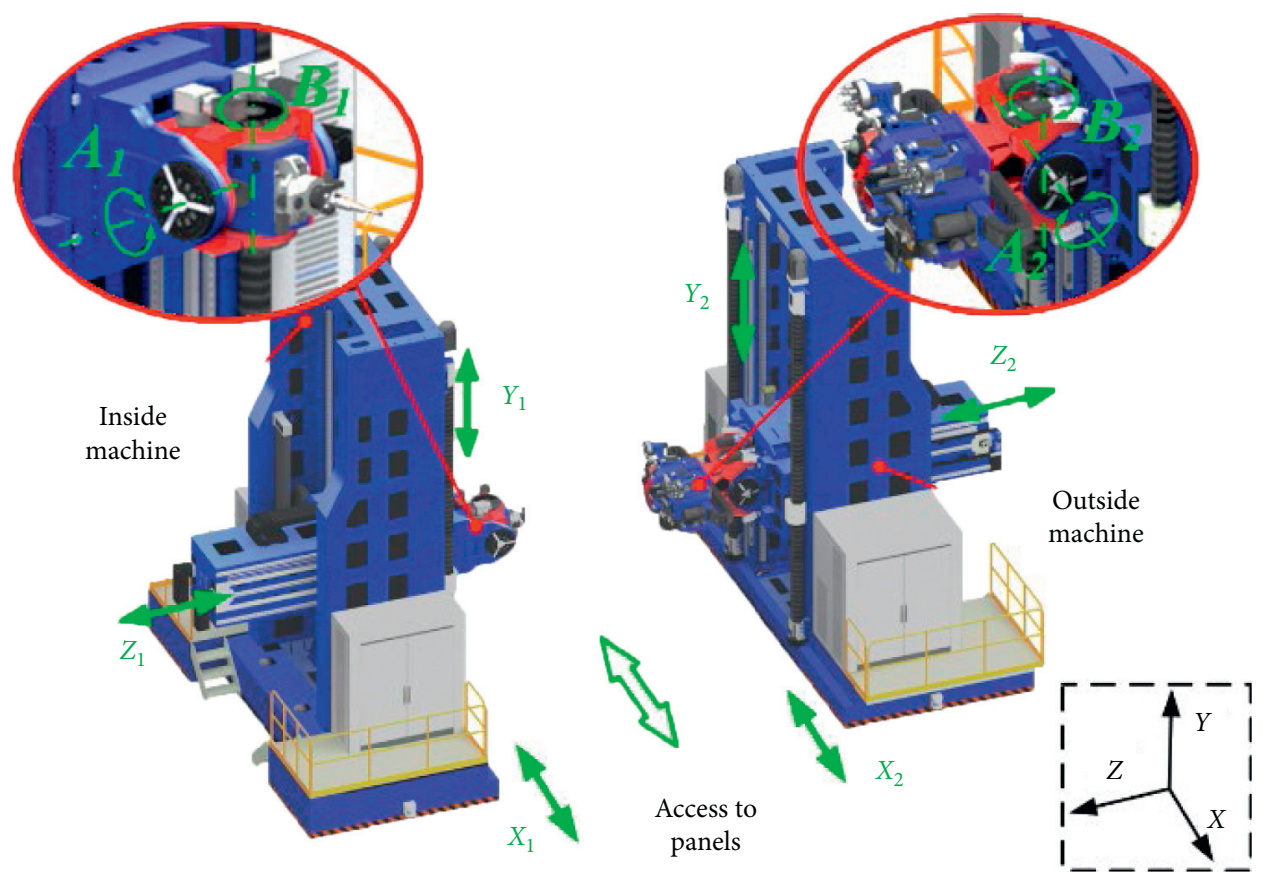

FIGURE 1: Structure of the dual-machine riveting system.

traditional automatic riveting system. In addition to the fact that the deformation error of machine is much bigger than that of traditional riveting machine, it is extremely difficult to accurately identify the stiffness model of machine in the whole machining space because the posture of the dualmachine riveting system varies a lot, and the experimental measurement workload is unbearable. Therefore, an improved riveting control method based on hybrid position/ force control is proposed in this paper to compensate the machine deformation, ensuring the riveting quality.

The riveting actuator of end-effector is driven by electric power servo, which, compared with pneumatic and hydraulic power, has the advantages of simple structure, large operation flexibility, and so forth. Speed, accuracy, and response ability are more reliable. The structure of the riveting actuator is shown in Figure 2, whose drivetrain adopts screw-nut pair. The servo motor drives the screw to rotate through the synchronous pulleys, and the nut converts the rotation motion into the translation motion, which drives the riveting die to feed, thus completing the riveting action. The linear direction of the feed is constrained by the linear guide pair. The force sensor is mounted on the back of the synchronous pulley, which can sample the data of riveting force during the rivet formed in real time. The linear scale is mounted under the feed platform to measure the position of riveting die.

2.2. Analysis of Force-Induced Deformation. The geometric error of machine tool exists and is compensated based on kinematic modeling to ensure the alignment of dual-machine system, which has been improved through cooperative calibration and compensation method by Zhao et al. [23, 24]. When a series mechanism is subjected to a unidirectional

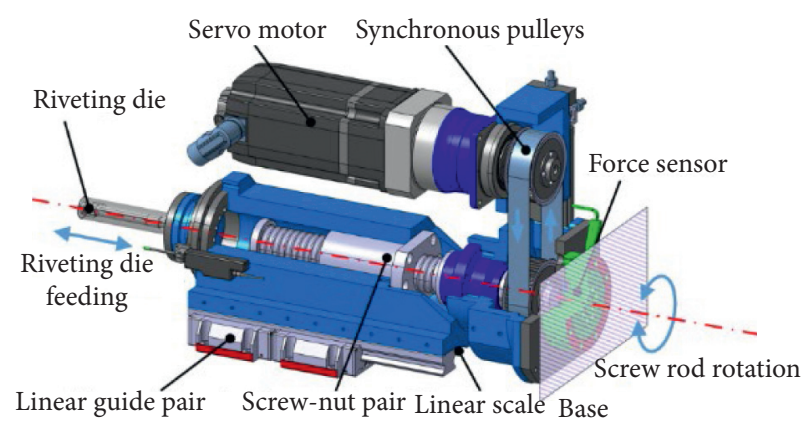

FIgURE 2: Structure of the riveting actuator.

external force, its end deformation is mainly translation deformation and follows a strict linear relationship with the external force $[26,27]$. The stiffness coefficient is related to the current posture of the mechanism. The deformation of the dual-machine riveting system is also mainly the backward deformation along the riveting force direction, and the deformation should be linear relationship with the riveting force. As shown in Figure 3, the gray entity represents the initial state of the riveting machine, and the green dotted line indicates the force-induced deformation of the riveting machine during rivet formed, where $P_{i}$ represents the inside machine deformation and $P_{o}$ represents the outside machine deformation. The feed distance of the riveting die is set according to the desired driven head height, so it will lead to insufficient riveting, even if the riveting die reaches the preset position. Insufficient riveting results in the riven head $P_{i}+P_{o}$ higher than the desired value. Meanwhile, the rivet manufactured head cannot stay in contact with the countersink affected by the retreat of outside machine, which will create gapping in the countersink, under the head. "This displacement" of the manufactured head also effect a change 


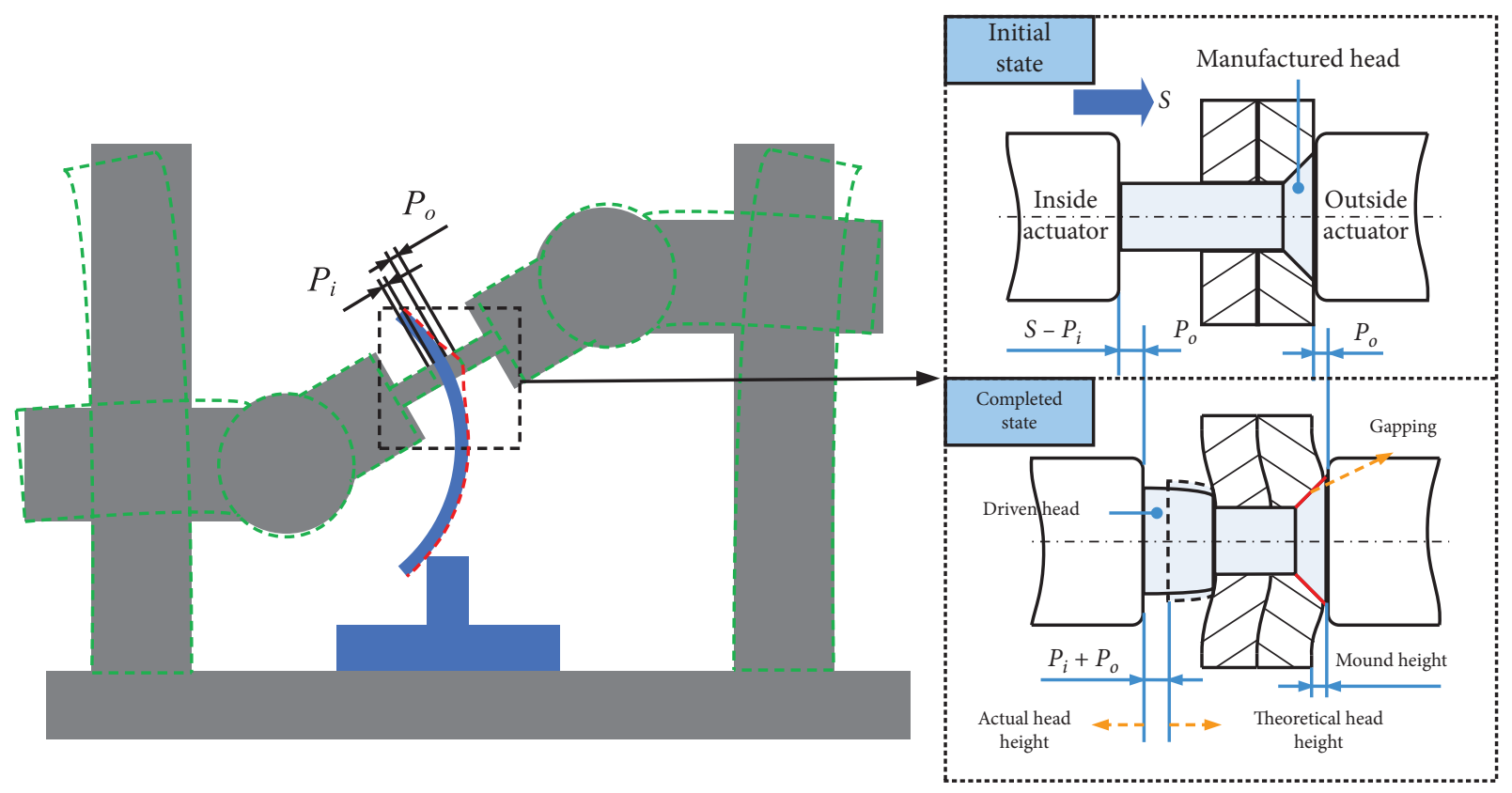

FIgURE 3: Riveting defects caused by machine deformation.

of shape in the plates, and the expansion of plates creates a mound, which reflects the aerodynamic shape and dealing of panels. Therefore, the mound height is also an important assessment index to make quantity appraise of riveting quality.

The position relation between the pressure foot and the rivet die does not change after the machine positioning to the riveting position. The pressure foot always pressures on the panel under the drive of cylinders, while the rivet die will fall back with the force-induced deformation of the machine during the rivet process. Therefore, the change of position between the pressure foot and the rivet die can be measured by length gauge, which has nothing to do with the geometric error of the machine tool.

2.3. Dynamics of Riveting Actuator. The flexible transmission chain of the machine should be considered in the modeling according to the analysis of the machine deformation. As shown in Figure 4, the machine deformation is treated as a spring link in this paper. Obviously, the influence of machine deformation on force control is mainly to weaken the direct force induction ability and reduce the force following performance. In order to ensure the accuracy and efficiency of riveting force control during the rivet formed, the ideal control performance should be able to accurately track the riveting force input signal under steady-state and high bandwidth conditions.

Since the relationship between the machine deformation and the output force has been established, coupled with the servo motor model and the axis drivetrain, the block diagram of the system dynamics shown in Figure 5 can be obtained, where the main parameters are defined in Table 2. $\tau_{m}$ and $\omega_{m}$ are the output torque and the angular velocity of the motor, respectively. $T_{k}$ is the transmission ratio of rotary

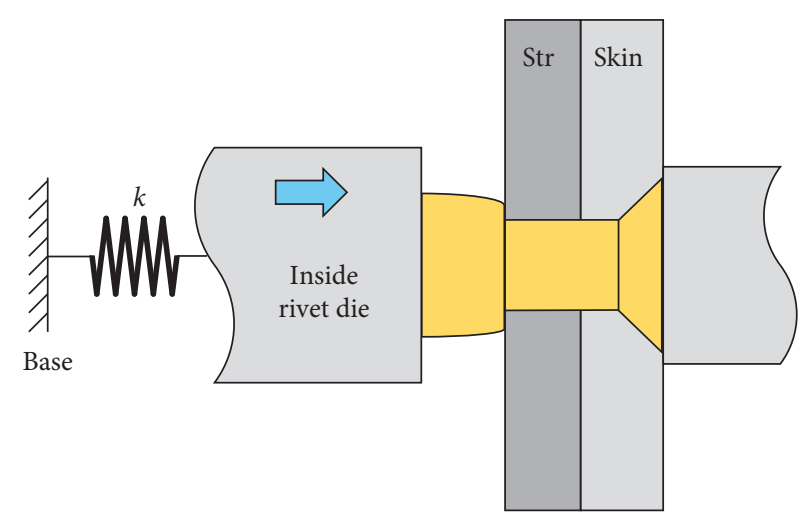

FIgURE 4: Flexible link of the actuator.

motion to translation motion, as the following formula expressed:

$$
T_{k}=\frac{p}{2 \pi}
$$

According to the block diagram shown in Figure 5, the nominal model of the riveting actuator can be expressed as,

$$
\mathrm{P}_{n}(s)=\frac{F_{\text {out }}}{V_{\text {in }}}=\frac{T_{k} k K_{V} K_{p} K_{m}}{K_{m} K_{e} s+\left(L_{m} s+R_{m}+K_{p} K_{f}\right)\left(J s^{2}+B s+T_{k}^{2} k\right)} .
$$

Thus, it can be seen that the equivalent stiffness $k$, which reflects the machine deformation, exists in the nominal model of the riveting system, and the stiffness of machine varies with the posture in the machining space, which results in the change of the dynamics of the system itself. In other words, the dynamics of the riveting actuator is uncertain compared with a single linear model. In addition to the 


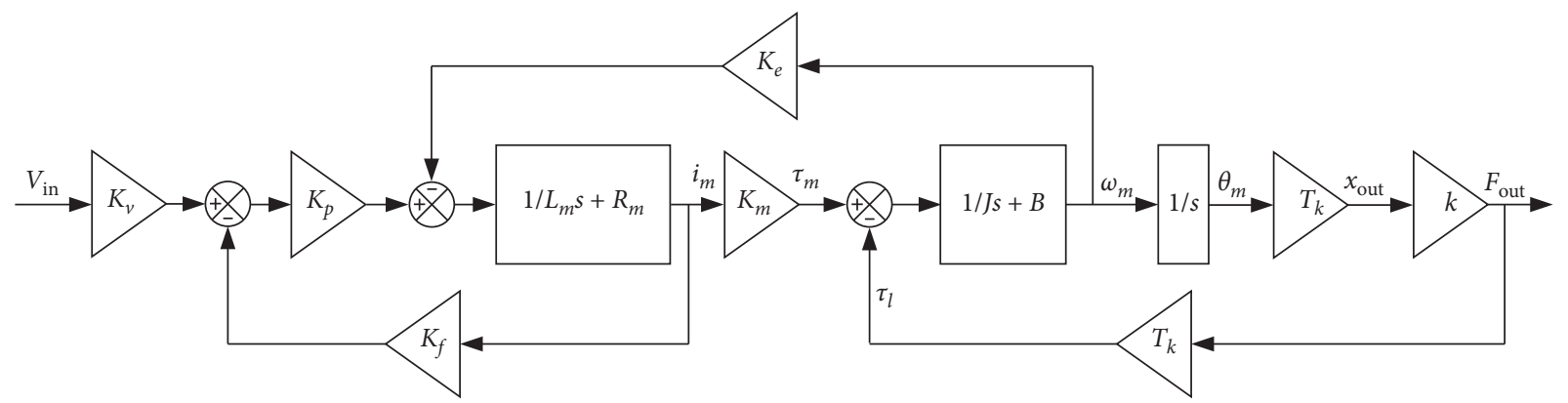

FIGURE 5: Block diagram of the system dynamics.

stiffness parameter of the machine, there are many uncertain factors during the system modeling, including the simplification of the drivetrain and the linearization of the servo motor. The multiplicative uncertainty of the model can be described as

$$
F_{\text {out }}=\mathrm{P}_{n}(s)\left(1+\Delta(s) W_{3}(s)\right) V_{\text {in }},
$$

where $\Delta(s)$ is a variable stable transfer function and satisfies $\Delta(s)_{\infty} \leq 1 . W_{3}(s)$ is the stable boundary function of multiplicative uncertainty.

\section{Hybrid Position/Force Control Design}

3.1. Position Controller Design. The end-effector of the outside machine not only integrates the riveting actuator shown in Figure 2 but also integrates the spindle and pressing foot. The pressing foot on both sides will clamp the panels to eliminate the gap between sheets before the riveting begins, and in the following inserting and riveting processing, the pressing foot clamps the panel all the time, which provides a stable condition for riveting. The pressing foot is driven by cylinders, so the clamping force can be adjusted by setting the cylinder pressure.

From the above analysis, the outside riveting die cannot resist the rivet manufactured head during rivets formed, which leads to the riveting defect. However, the pressing foot is pneumatic, always pressing the surface of the skin, not affected by the machine deformation. Therefore, a length gauge is installed between the actuator and the pressing foot to measure the displacement of the pressing foot relative to the outside machine, whose principle is shown in Figure 6, where $\delta$ is the position change of the pressing foot relative to the actuator, equivalent to the deformation error of the outside machine. The machine deformation can be obtained by reading the change of the value of the length gauge.

The position compensation block diagram is shown in Figure 7. The position of the riveting die is fed back by the linear scale, and the position change of the pressing foot relative to the actuator is added to the position of closed loop of the riveting die as compensation signal. At this time, the riveting die feed can maintain the relative unchanged with the pressing foot when the outside machine retreats, that is, the position of the rivet manufactured head is unchanged, thus eliminating the gapping.
The real-time compensation signal based on the position change of the pressing foot may cause unnecessary noise disturbance, so a low-pass filter is added to the position compensation to eliminate unwanted high frequency noise to ensure the stability of the system. The position of the pressing foot varies up to $0.7 \mathrm{~mm}$, and the frequency is $0.5-3 \mathrm{~Hz}$ during the rivet formed. This part of the position information of the foot should be "protected" to compensate the riveting die, so a 2-order Butterworth low-pass filter is adopted in this paper, whose amplitude-frequency response formula is expressed as

$$
|H(\omega)|=\frac{1}{\sqrt{1+\left(\omega / \omega_{c}\right)^{4}}},
$$

where $|H(\omega)|$ is the attenuation amplitude and $\omega_{c}$ is the cutoff frequency.

3.2. Force Controller Design. An advanced force control strategy is adopted to overcome the limitation of the flexible axis in this paper, whose block diagram is shown in Figure 8. The nominal model of the riveting actuator established above, $\mathrm{P}_{n}(s)$ in formula (2), is utilized for the design of each controller in this paper. The DOB is designed based on the inverse model with a Q filter, and the feedforward controller $K_{\mathrm{ff}}(s)$ is designed as the inverse model by a low-pass filter. A $H_{\infty}$ controller is applied as $K_{\mathrm{fb}}(s)$, which can be calculated using the MATLAB robust control toolbox according to the uncertainty.

3.2.1. The $K_{f b}(s)$ Controller. The feedback controller is designed using the $H_{\infty}$ mixed sensitivity method, whose framework is shown in Figure 9. $W_{1}(s), W_{2}(s)$, and $W_{3}(s)$ are the weighting functions of the tracking error $e$, control input $\Delta u$, and the system output $F_{\text {out }}$. The key of $H_{\infty}$ controller design is to determine the appropriate weighting functions to calculate the controller, where $W_{1}(s)$ has the low-pass filtering characteristic, $W_{3}(s)$ has the high-pass filter characteristic, and $W_{2}(s)$ is usually weighting constant. The values of the parameters in the nominal model are shown in Table 2. According to the following identification experimental results in Section 4, a proper boundary function is selected for uncertainty expressed as 


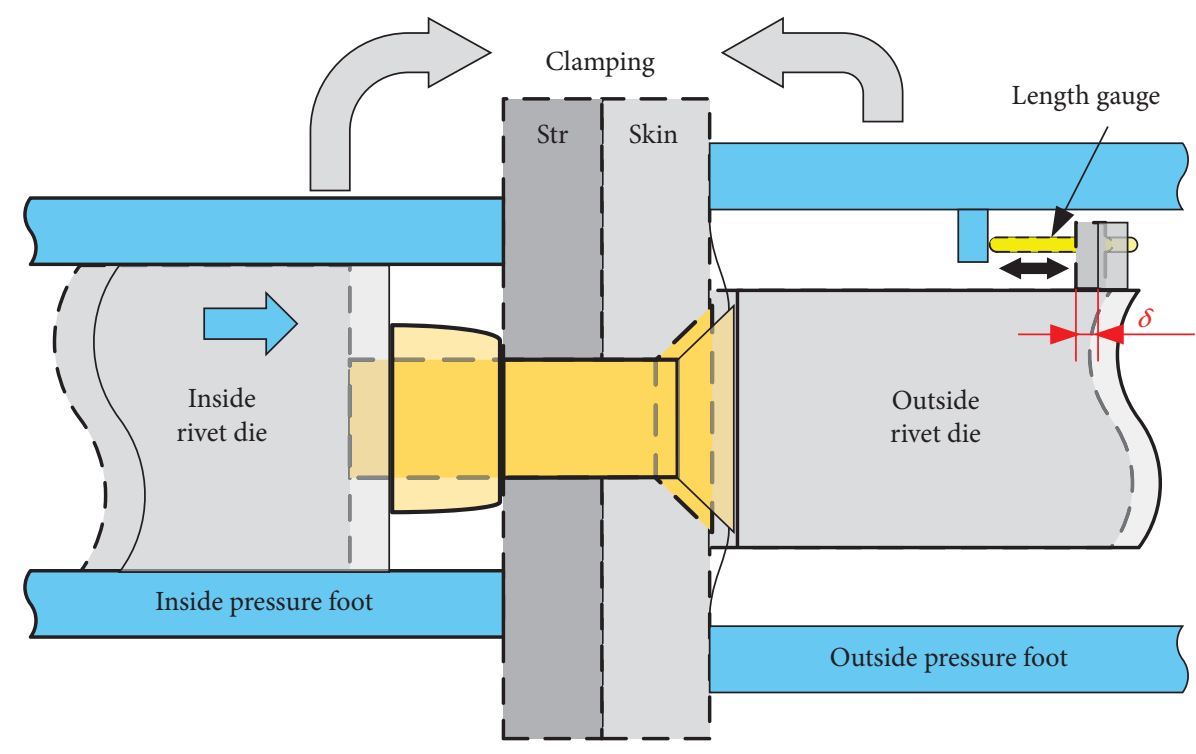

FIGURE 6: Compensation principle based on foot position.

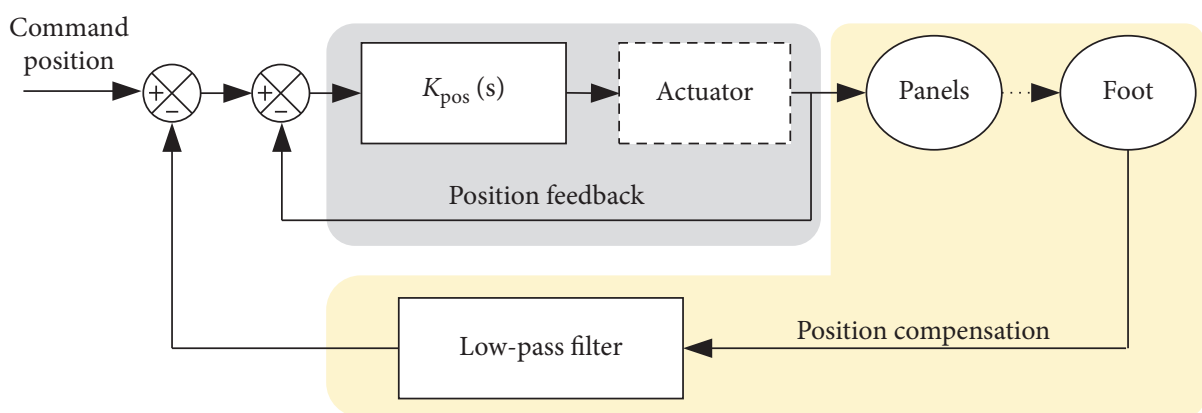

Figure 7: Position compensation block diagram.

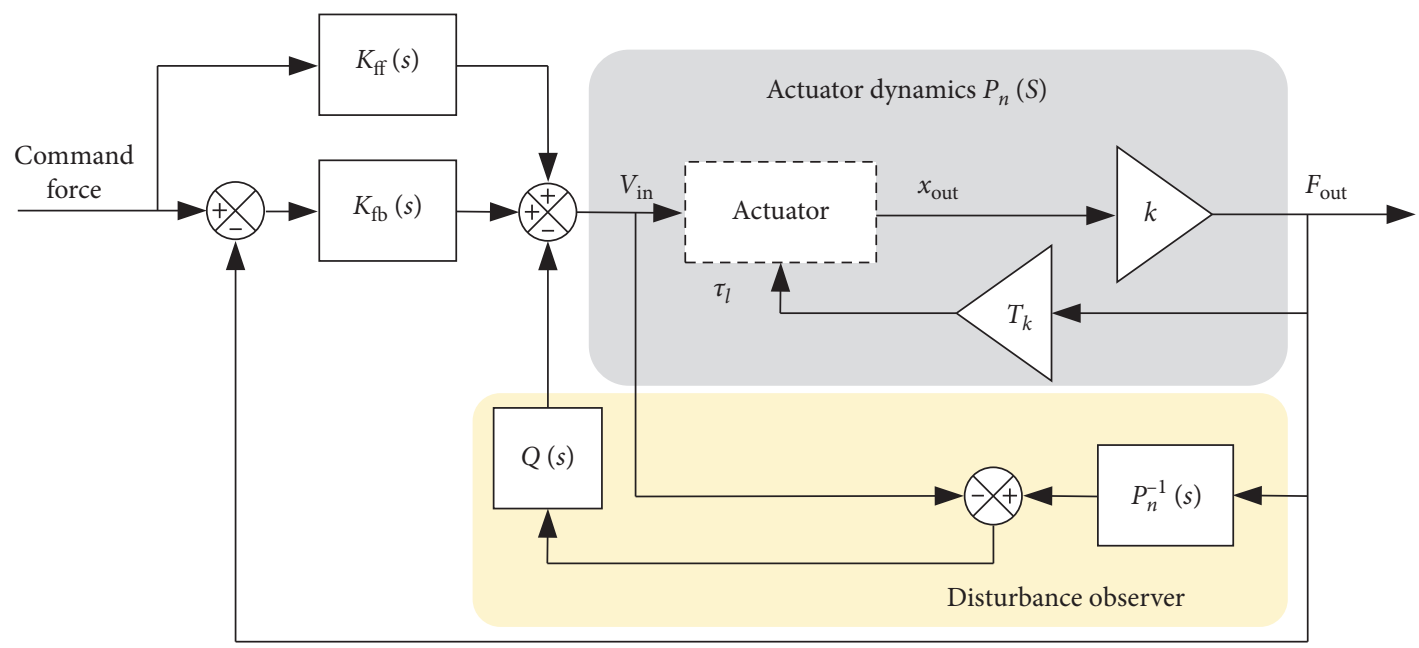

FigURE 8: Force control block diagram. 


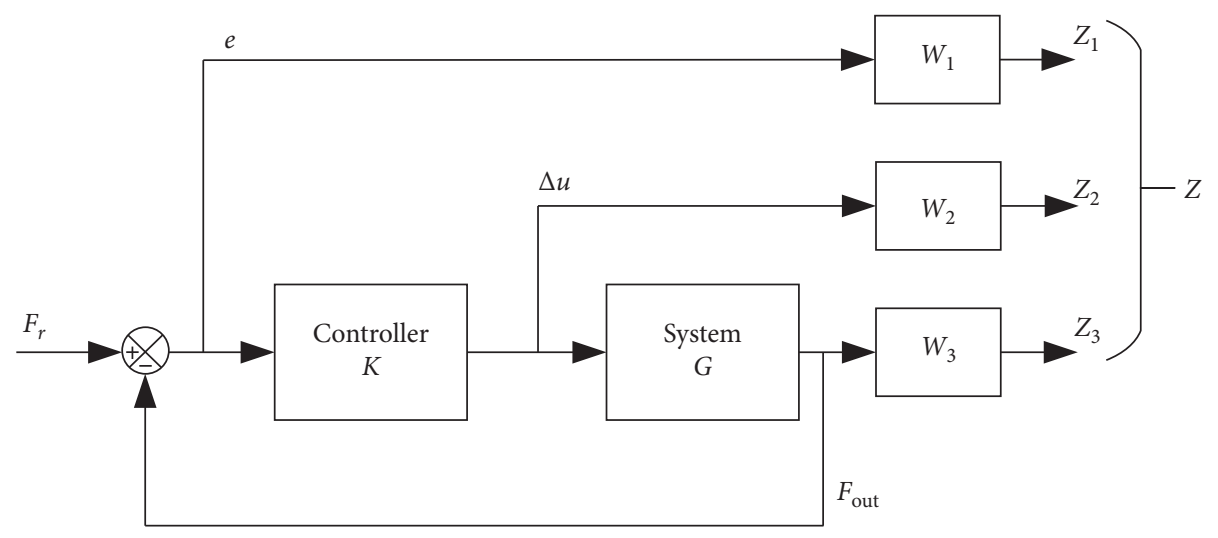

Figure 9: Block diagram of the $H_{\infty}$ framework.

$$
\left\{\begin{array}{l}
W_{1}(s)=\frac{0.74 s+47.62}{s+0.095}, \\
W_{2}(s)=0.02 \\
W_{3}(s)=\frac{0.01 s+0.3745}{0.00031 s+1} .
\end{array}\right.
$$

The sensitivity $S(s)$ and the complementary sensitivity $T(s)$ are shown in Figure 10, which shows that the designed controller meets the performance index requirements $\left\|W_{1}(s) S(s)\right\|_{\infty} \leq 1,\left\|W_{3}(s) T(s)\right\|_{\infty} \leq 1$.

3.2.2. The Disturbance Observer. Since a relatively accurate nominal model has been obtained, the selection of $Q$ filter is the key to design the DOB, which should attenuate the uncertainty of the model as much as possible and retain the disturbance information. Therefore, there is a compromise between robust stability and tracking performance in DOB design. The selection of $Q$ filter must meet the following conditions: (1) $Q(s)$ should be a low-pass filter with a steadystate gain of 1 and (2) the amplitude of $Q(s)$ should be less than $W_{3}(s)$ 's at all frequencies, where $W_{3}(s)$ is the stable boundary function of multiplicative uncertainty. A secondorder low-pass filter, as shown below, is adopted in this paper.

$$
Q(s)=\frac{\omega_{Q}^{2}}{s^{2}+\sqrt{2} \omega_{Q} s+\omega_{Q}^{2}},
$$

where $\omega_{Q}$ represents the cutoff frequency of $Q(s)$. According to the filter selection conditions, a proper cutoff frequency of $100 \mathrm{rad} / \mathrm{s}$ is selected to deal with the model uncertainty. The amplitude curve of $W_{3}^{-1}(s)$ is always higher than that of $Q(s)$, as shown in Figure 11 .

3.2.3. The $C_{f f}(s)$ Controller. In order to achieve good riveting force tracking performance, $K_{\mathrm{ff}}(s)$ is added to the force control strategy as a feedforward controller, which is designed as the inverse nominal model multiplied by a lowpass filter, as shown below, to make $K_{\mathrm{ff}}(s)$ proper:

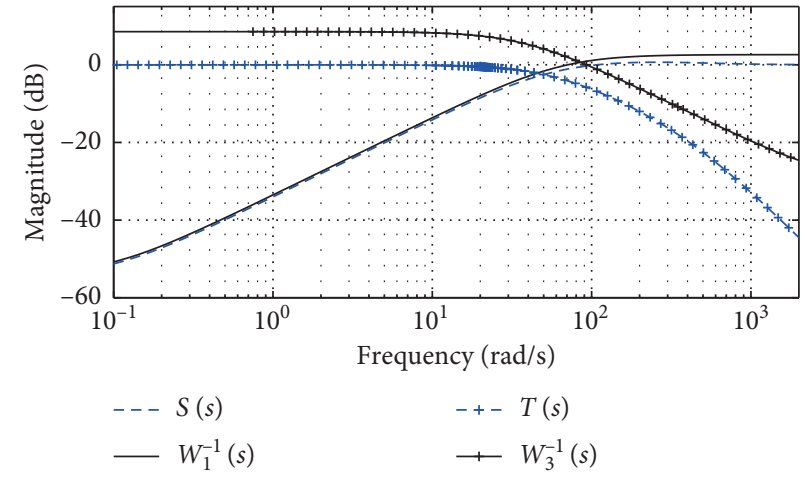

FIGURE 10: System characteristics.

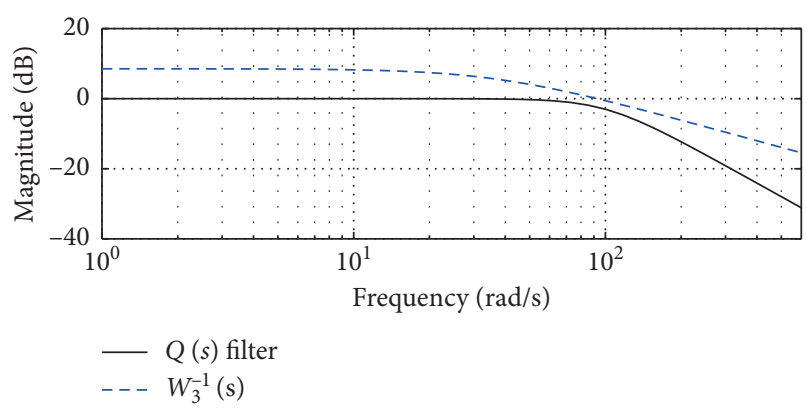

Figure 11: Amplitude curves of $Q(s)$ and $W_{3}^{-1}(s)$.

$$
K_{\mathrm{ff}}(s)=Q_{2}(s) \cdot P_{n}^{-1}(s) .
$$

\section{Experiment}

4.1. Experiment Setup. The servo-control system is shown in Figure 12. The CNC system of the dual-machine riveting system is Siemens 840Dsl, and the riveting actuator adopts QMP motion control card and motion control software of Danaher. Communication between computer and machine is realized based on TCP/IP protocol, and QMP motion control card realizes the logic control of servo motors based on the SynqNet bus, which is a high-performance all-digital synchronous motion control network developed by Danaher. The servo motor used is AKM-65 N from 


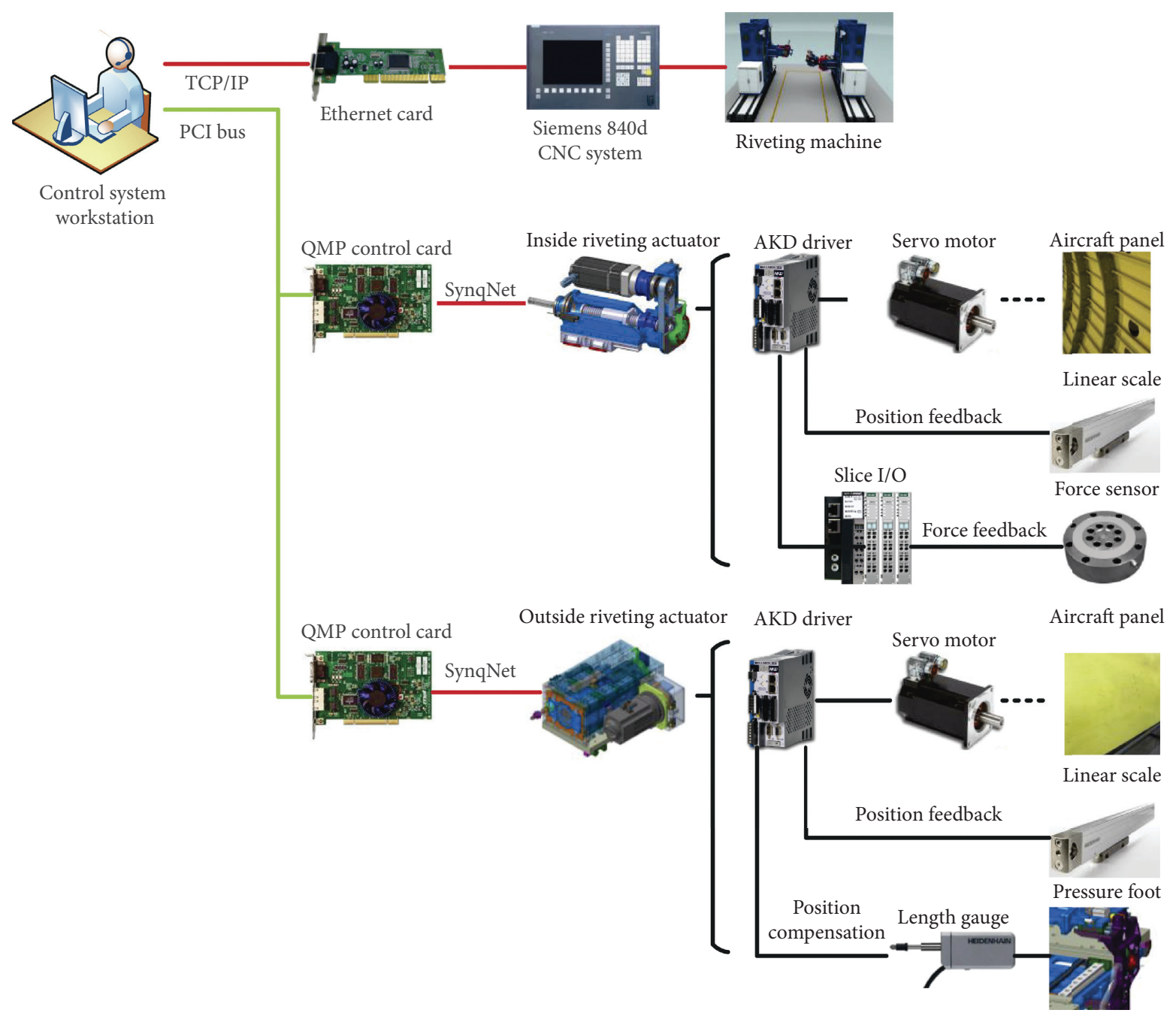

Figure 12: Servo-control system.

Kollmorgen of Danaher. The linear scale is the LC series from Heidenhain, with an accuracy of $0.005 \mathrm{~mm}$. The force sensor is the $\mathrm{U} 10 \mathrm{M}$ from HBM. The parameter values of the nominal model are shown in Table 1.

The aviation aluminum alloy 7075-T7451 sheet and countersink head rivet NAS1097AD5-6 are adopted in the riveting experiment. The geometric dimensions of specimens are shown in Table 2. The selection of the process parameters and quality evaluation refer to standard aircraft handbook [28], and the precision should satisfy the tolerance as follows:

$$
\begin{array}{r}
D=(1.5 \pm 0.1) d, \\
h_{\min } \geq 0.4 d,
\end{array}
$$

where $D$ represents the driven head diameter, $d$ represents the rivet diameter, and $h_{\min }$ represents the minimum driven head height. The mound height allowed is $0 \sim 0.05 \mathrm{~mm}$.

In the experiment, the riveting installation of 10 rivets is completed under different postures. The machining steps of riveting experiments are shown in Figure 13, and
TABLE 1: Values of model parameters.

\begin{tabular}{lccc}
\hline Items & Symbols & Unit & Value \\
\hline Screw's lead & $p$ & $\mathrm{~mm}$ & 12 \\
Input coefficient & $K_{V}$ & - & 0.00138 \\
Current gain & $K_{p}$ & - & 5 \\
Current feedback & $K_{f}$ & - & 1 \\
gain & $K_{m}$ & $\mathrm{~N} \cdot(\mathrm{m} / \mathrm{A})$ & 1.38 \\
Torque coefficient & $K_{e}$ & $\mathrm{~V} /(\mathrm{rad} / \mathrm{s})$ & 0.8484 \\
$\begin{array}{l}\text { Back-EMF coefficient } \\
\text { Motor inductance }\end{array}$ & $L_{m}$ & $H$ & 0.0034 \\
$\begin{array}{l}\text { Motor resistance } \\
\text { Overall moment of }\end{array}$ & $R_{m}$ & $\Omega$ & 0.42 \\
inertia & $J$ & $\mathrm{Kg} \cdot \mathrm{m}^{2}$ & 0.024 \\
$\begin{array}{l}\text { Overall viscous } \\
\text { friction factor }\end{array}$ & $B$ & $\mathrm{~N} \cdot \mathrm{m} /(\mathrm{rad} / \mathrm{s})$ & 0.00096 \\
$\begin{array}{l}\text { Stiffness of the } \\
\text { machine }\end{array}$ & $k$ & $(\mathrm{~N} / \mathrm{m})$ & $2 \times 10^{7} \sim 5 \times 10^{7}$ \\
\hline
\end{tabular}

the posture of the riveting system is adjusted for the next set of riveting after completing the installation of one set of rivets. 
TABle 2: Parameters of specimens.

\begin{tabular}{lcc}
\hline Items & Values & Units \\
\hline Stringer thickness & 2 & $\mathrm{~mm}$ \\
Skin thickness & 1.5 & $\mathrm{~mm}$ \\
Rivet hole & 4.07 & $\mathrm{~mm}$ \\
Rivet diameter & $(5 / 32)$ & Inches \\
Rivet length & $(6 / 16)$ & Inches \\
Rivet driven head height & 2 & $\mathrm{~mm}$ \\
\hline
\end{tabular}

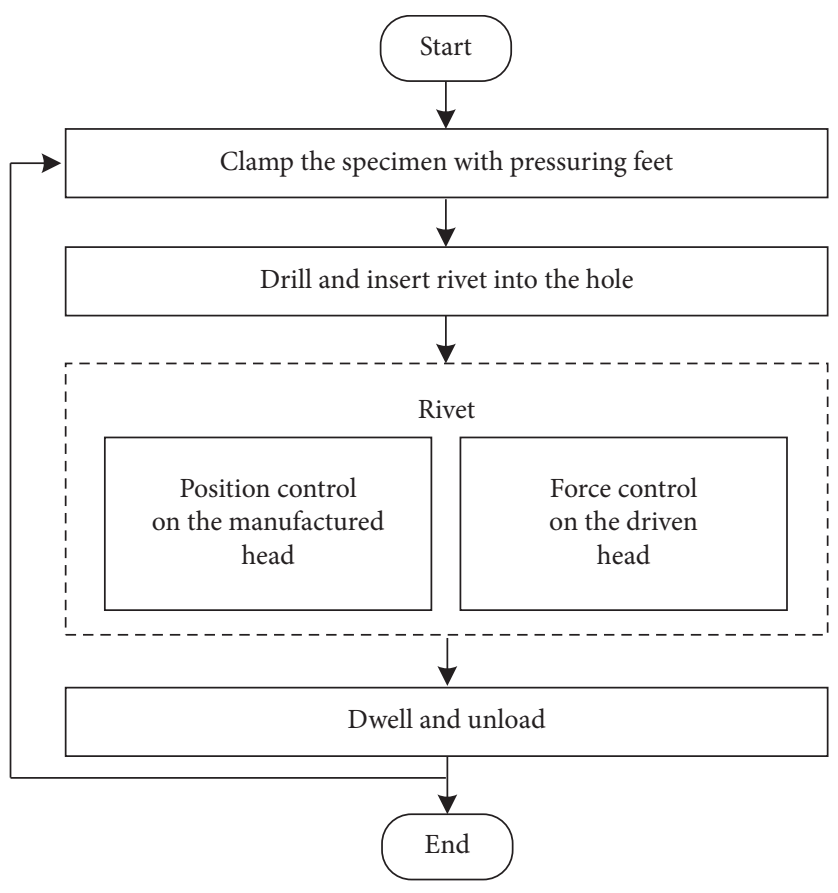

FIGURE 13: Flowchart for riveting experiments.
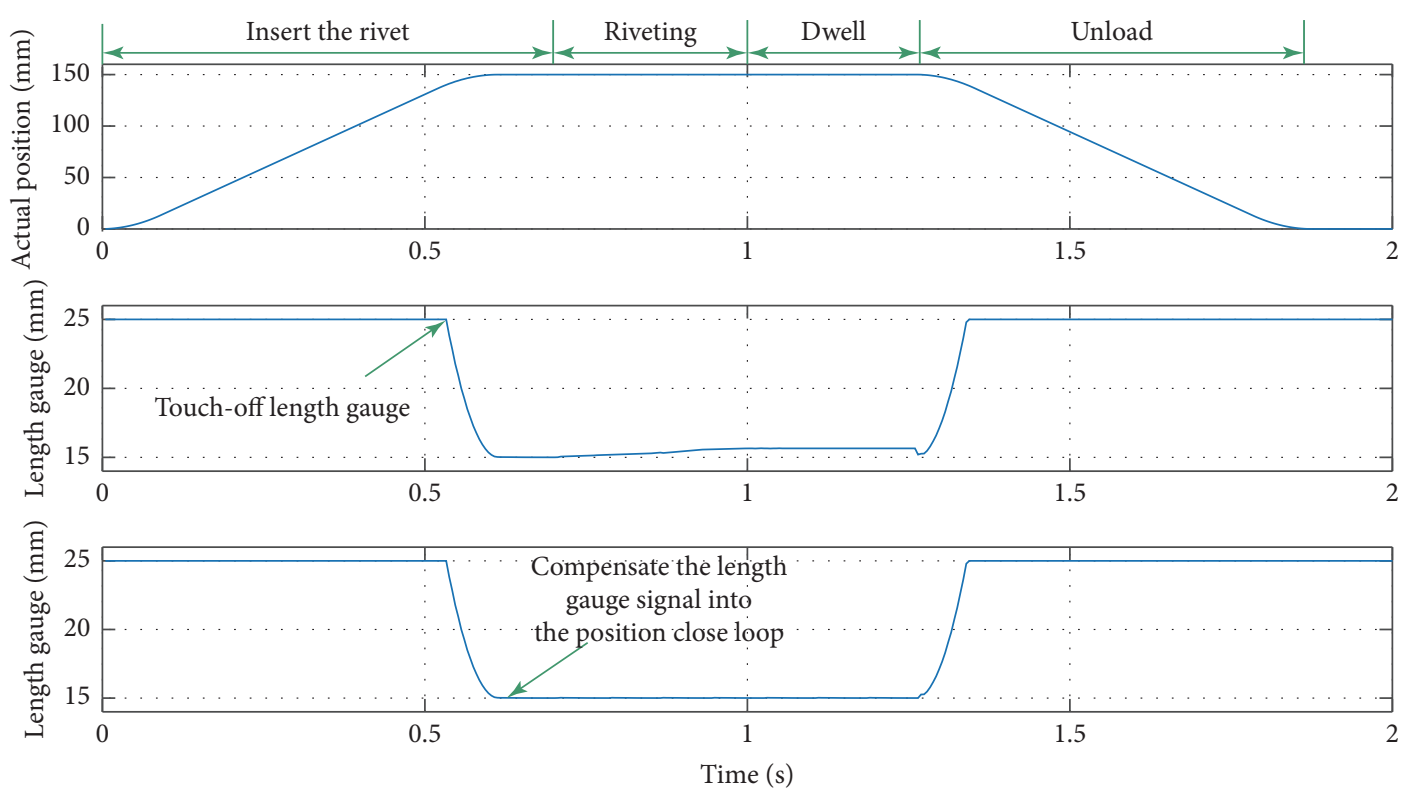

FIgUre 14: Position curve of the outside riveting die during riveting. 


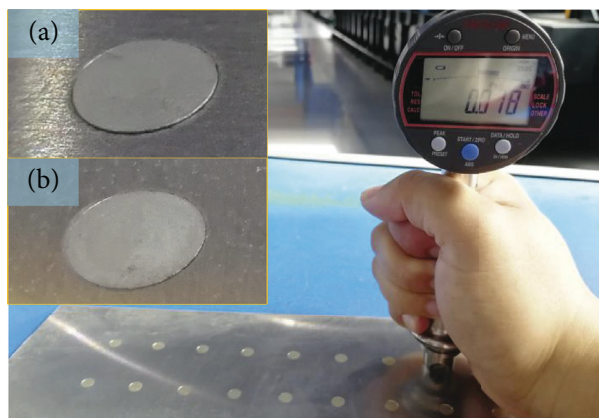

FIGURE 15: Measuring the mound height of the manufactured head: (a) the head using a legacy process and (b) the head using the improved process with foot position compensation.
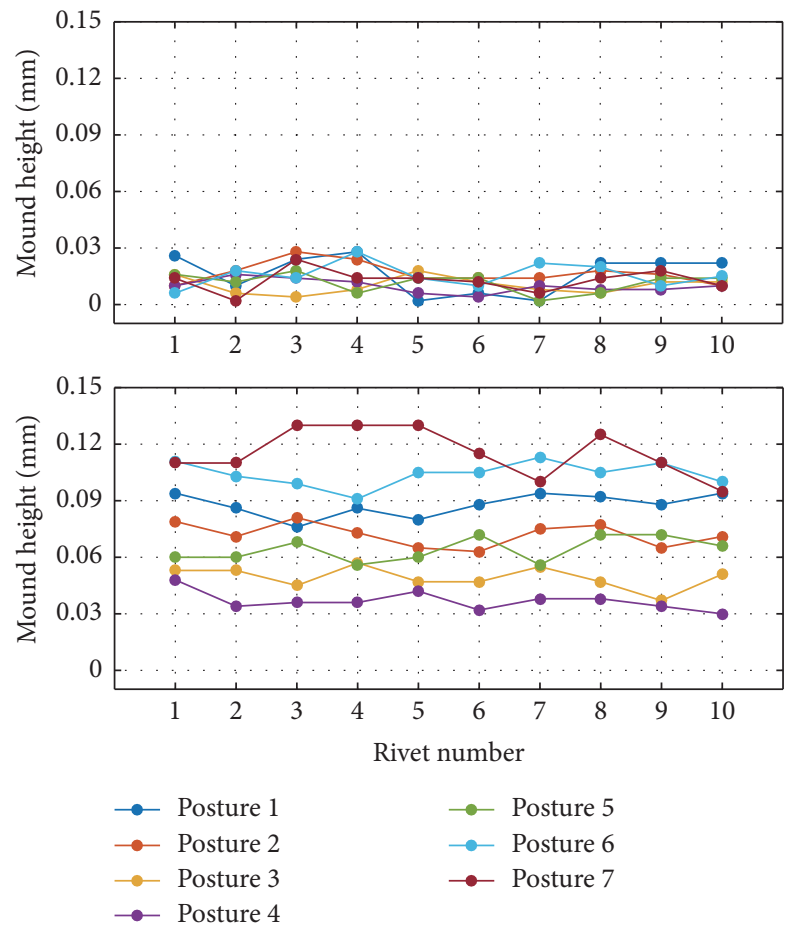

FIGURE 16: Measurement results of the mound height.

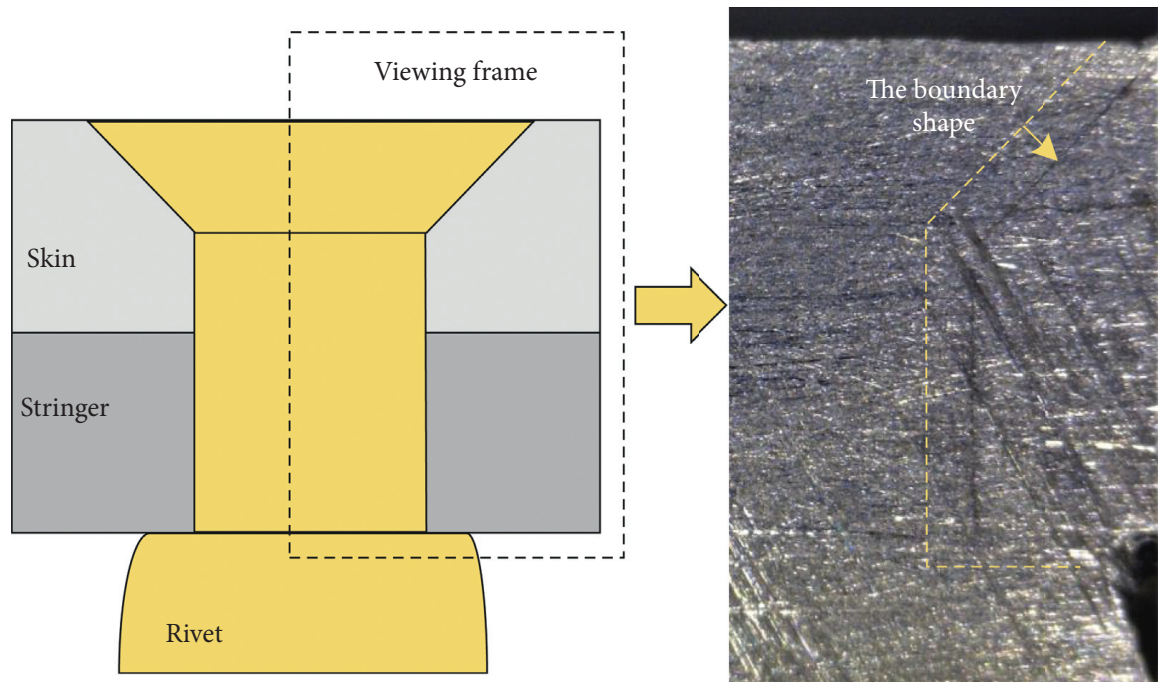

(a)

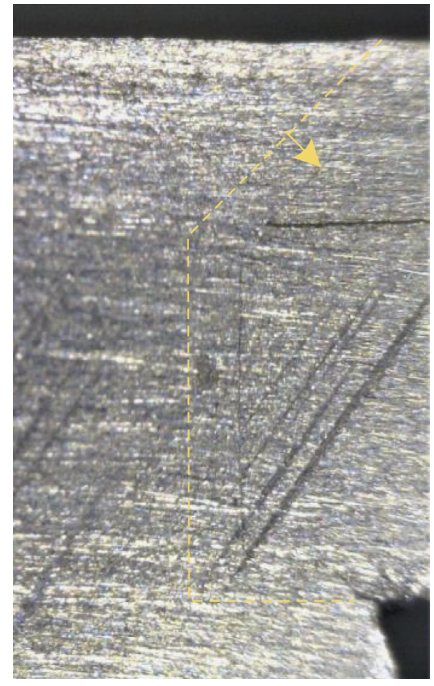

(b)

Figure 17: A cross section view of a riveted joint using (a) a legacy process and (b) the improved process with foot position compensation. 


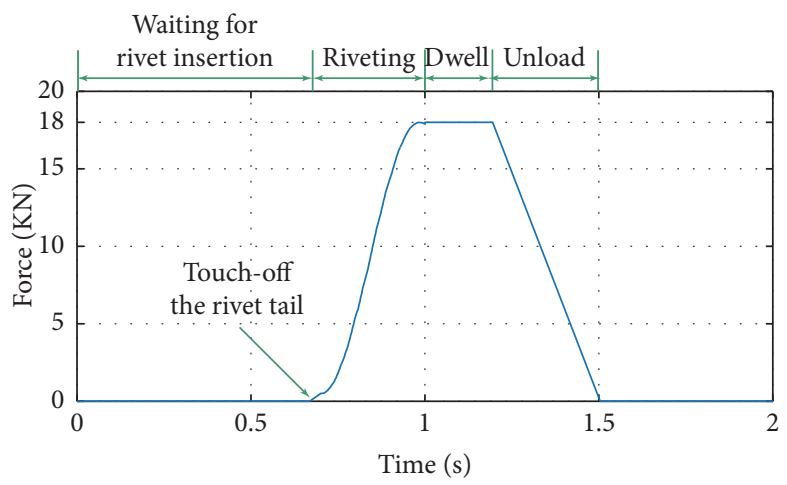

FIgURE 18: Force curve of the inside riveting die during riveting.

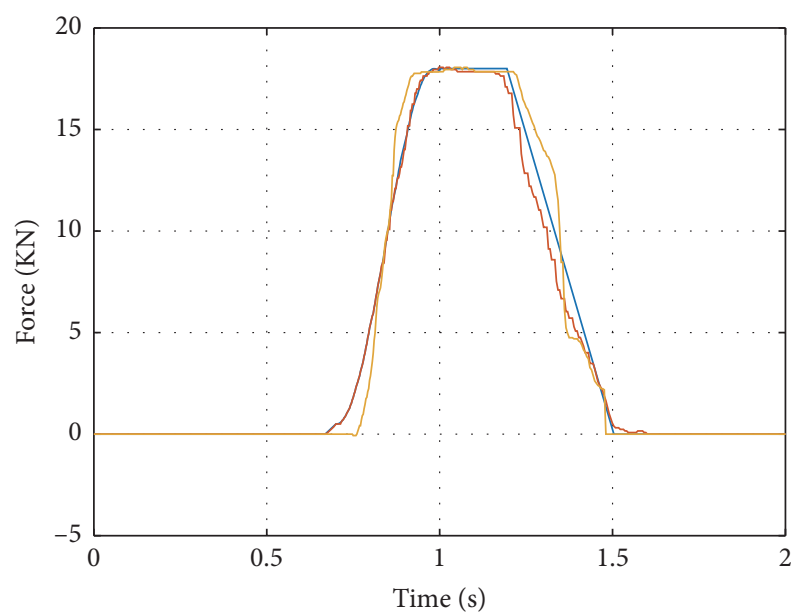

Force command

Force output with feedforward control

Force output without feedforward control

(a)

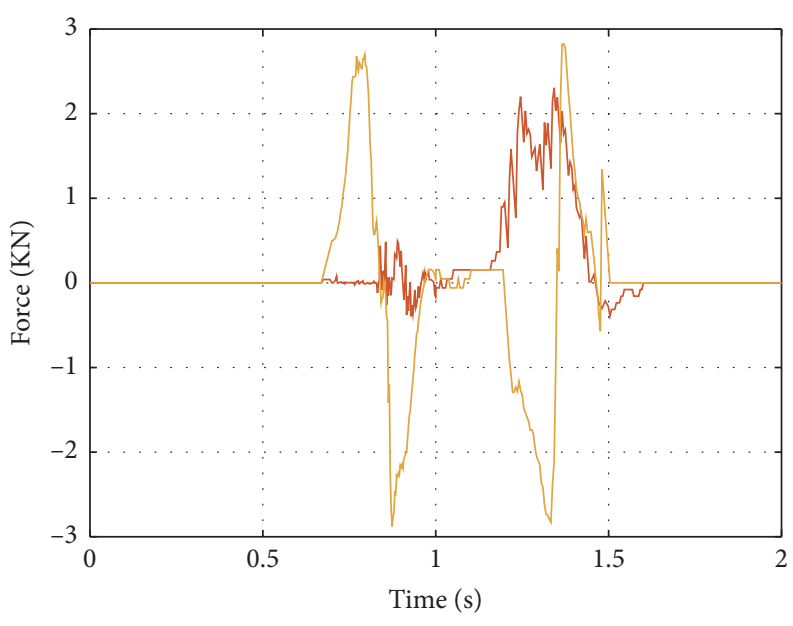

_ Tracking error with feedforward control

__ Tracking error without feedforward control

(b)

FIGURE 19: Verification of the feedforward controller performance.

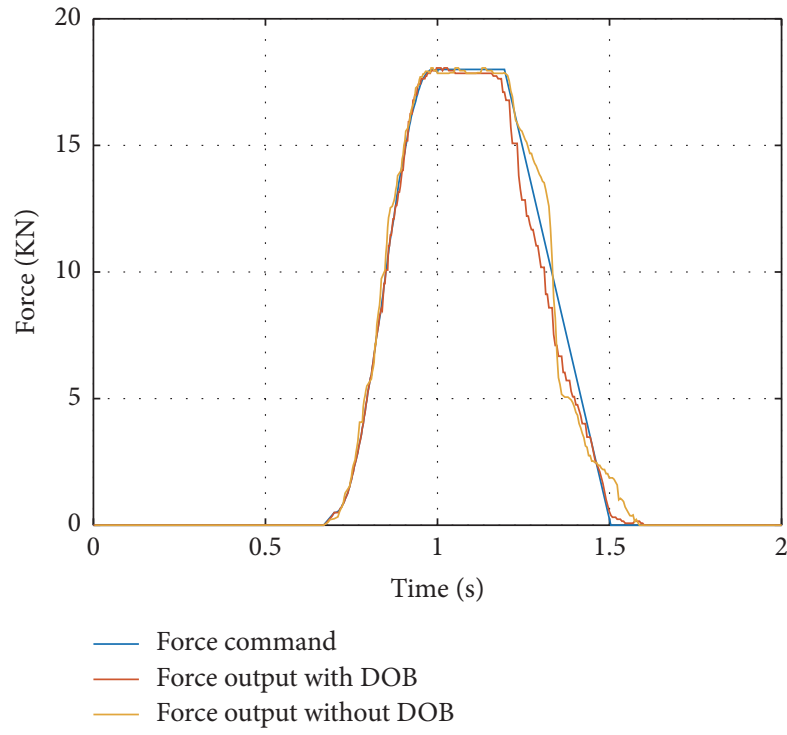

(a)

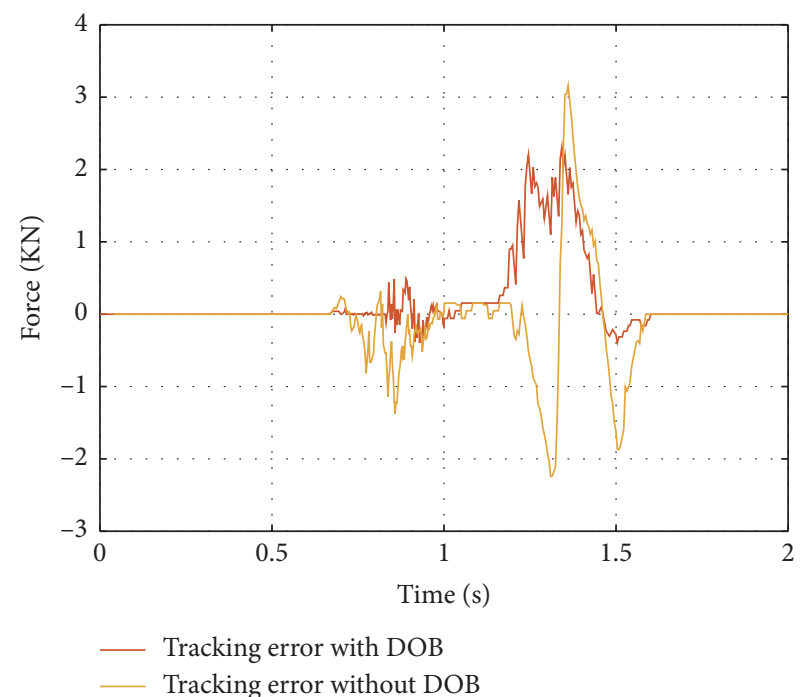

(b)

FIgURE 20: Verification of the DOB performance. 
TABLE 3: Completed experimental results.

\begin{tabular}{|c|c|c|c|c|c|}
\hline Posture & Serial number & $H(\mathrm{~mm})$ & $F(\mathrm{KN})$ & $S(\mathrm{~mm})$ & $\delta(\mathrm{mm})$ \\
\hline \multirow{10}{*}{1} & $1-1$ & 2.032 & 17.99 & 4.11 & 0.312 \\
\hline & $1-2$ & 2.028 & 18 & 4.14 & 0.298 \\
\hline & $1-3$ & 2.028 & 18.02 & 4.14 & 0.298 \\
\hline & $1-4$ & 2.028 & 18.02 & 4.13 & 0.306 \\
\hline & $1-5$ & 2.032 & 18.01 & 4.14 & 0.298 \\
\hline & $1-6$ & 2.028 & 18 & 4.14 & 0.306 \\
\hline & $1-7$ & 2.031 & 18.03 & 4.16 & 0.294 \\
\hline & $1-8$ & 2.028 & 18.01 & 4.15 & 0.292 \\
\hline & $1-9$ & 2.031 & 17.99 & 4.14 & 0.338 \\
\hline & $1-10$ & 2.029 & 18.01 & 4.14 & 0.332 \\
\hline \multirow{10}{*}{2} & $2-1$ & 1.998 & 18.03 & 3.92 & 0.268 \\
\hline & $2-2$ & 1.998 & 18.02 & 3.91 & 0.262 \\
\hline & $2-3$ & 1.990 & 18.02 & 3.90 & 0.270 \\
\hline & $2-4$ & 2.002 & 18 & 3.89 & 0.252 \\
\hline & $2-5$ & 1.992 & 17.99 & 3.87 & 0.258 \\
\hline & $2-6$ & 1.992 & 18.02 & 3.89 & 0.216 \\
\hline & $2-7$ & 2.000 & 17.99 & 3.89 & 0.274 \\
\hline & $2-8$ & 1.992 & 18.01 & 3.88 & 0.274 \\
\hline & $2-9$ & 1.982 & 17.98 & 3.88 & 0.274 \\
\hline & $2-10$ & 1.996 & 18.02 & 3.87 & 0.248 \\
\hline \multirow{10}{*}{3} & $3-1$ & 2.016 & 18.020 & 3.77 & 0.204 \\
\hline & $3-2$ & 2.016 & 17.990 & 3.74 & 0.192 \\
\hline & $3-3$ & 2.018 & 18.010 & 3.76 & 0.216 \\
\hline & $3-4$ & 2.016 & 18.000 & 3.76 & 0.196 \\
\hline & $3-5$ & 2.016 & 18.010 & 3.76 & 0.222 \\
\hline & $3-6$ & 2.022 & 18.010 & 3.74 & 0.214 \\
\hline & $3-7$ & 2.016 & 18.000 & 3.75 & 0.218 \\
\hline & $3-8$ & 2.022 & 17.980 & 3.74 & 0.226 \\
\hline & $3-9$ & 2.022 & 17.980 & 3.75 & 0.212 \\
\hline & $3-10$ & 2.016 & 17.990 & 3.74 & 0.192 \\
\hline \multirow{10}{*}{4} & $4-1$ & 2.084 & 18.01 & 3.71 & 0.163 \\
\hline & $4-2$ & 2.076 & 18.01 & 3.72 & 0.173 \\
\hline & $4-3$ & 2.086 & 18.01 & 3.72 & 0.173 \\
\hline & $4-4$ & 2.078 & 17.98 & 3.70 & 0.191 \\
\hline & $4-5$ & 2.07 & 18 & 3.75 & 0.189 \\
\hline & $4-6$ & 2.068 & 17.98 & 3.70 & 0.195 \\
\hline & $4-7$ & 2.08 & 17.97 & 3.68 & 0.183 \\
\hline & $4-8$ & 2.082 & 17.98 & 3.71 & 0.179 \\
\hline & $4-9$ & 2.07 & 18 & 3.70 & 0.184 \\
\hline & $4-10$ & 2.076 & 17.97 & 3.71 & 0.185 \\
\hline \multirow{10}{*}{5} & $5-1$ & 1.944 & 18.03 & 3.74 & 0.244 \\
\hline & $5-2$ & 1.936 & 18.01 & 3.71 & 0.242 \\
\hline & $5-3$ & 1.926 & 18.04 & 3.74 & 0.216 \\
\hline & $5-4$ & 1.936 & 18.02 & 3.73 & 0.224 \\
\hline & $5-5$ & 1.93 & 18.01 & 3.72 & 0.214 \\
\hline & $5-6$ & 1.938 & 18.01 & 3.72 & 0.224 \\
\hline & $5-7$ & 1.944 & 18.03 & 3.74 & 0.239 \\
\hline & $5-8$ & 1.942 & 18.06 & 3.74 & 0.224 \\
\hline & $5-9$ & 1.938 & 18.02 & 3.74 & 0.241 \\
\hline & $5-10$ & 1.944 & 18.01 & 3.73 & 0.236 \\
\hline \multirow{10}{*}{6} & $6-1$ & 2.016 & 17.98 & 3.78 & 0.336 \\
\hline & $6-2$ & 2.008 & 18.02 & 3.80 & 0.361 \\
\hline & $6-3$ & 2.004 & 18 & 3.79 & 0.354 \\
\hline & $6-4$ & 1.996 & 18 & 3.77 & 0.358 \\
\hline & $6-5$ & 2.01 & 18 & 3.79 & 0.376 \\
\hline & $6-6$ & 2.01 & 18 & 3.79 & 0.362 \\
\hline & $6-7$ & 2.018 & 18.02 & 3.81 & 0.332 \\
\hline & $6-8$ & 2.01 & 17.98 & 3.77 & 0.34 \\
\hline & $6-9$ & 2.022 & 18.03 & 3.93 & 0.339 \\
\hline & $6-10$ & 2.016 & 18 & 3.93 & 0.338 \\
\hline
\end{tabular}

TABle 3: Continued.

\begin{tabular}{cccccc}
\hline Posture & Serial number & $H(\mathrm{~mm})$ & $F(\mathrm{KN})$ & $S(\mathrm{~mm})$ & $\delta(\mathrm{mm})$ \\
\hline $7-1$ & 2.014 & 18.01 & 3.84 & 0.63 \\
& $7-2$ & 2.006 & 17.97 & 3.88 & 0.617 \\
& $7-3$ & 2.012 & 18.03 & 3.90 & 0.614 \\
7 & $7-4$ & 2.012 & 18.02 & 3.91 & 0.602 \\
& $7-5$ & 2 & 17.97 & 3.89 & 0.629 \\
& $7-6$ & 2.016 & 18.01 & 3.79 & 0.608 \\
& $7-7$ & 2.008 & 18.01 & 3.82 & 0.634 \\
$7-8$ & 2 & 18 & 3.83 & 0.618 \\
& $7-9$ & 2.016 & 18 & 3.84 & 0.616 \\
$7-10$ & 1.998 & 18.02 & 3.90 & 0.614 \\
\hline
\end{tabular}

\subsection{Experiment Results}

4.2.1. Effect of Mound Height Control. The position curve of the outside riveting die during the rivet formed is shown as the upper chart in Figure 14. As we can see, the action of the outside riveting die includes the inserting rivet, resisting rivet manufactured head during riveting and dwelling, and unloading. The range of the length gauge is $25 \mathrm{~mm}$. With the feed of the outside riveting die, the length gauge contacts the pressing foot at $0.53 \mathrm{~s}$ and is compressed. The insertion is completed at $0.62 \mathrm{~s}$ shown as the medium chart in Figure 14.

The legacy process used in traditional riveting control method usually ignores the compensation on the manufactured-head side, so the outside rivet die stays still during the riveting process. The medium chart shows the change in the length gauge data under the traditional position control without compensation, which reflects the machine deformation during riveting. The relative position of the pressing foot and the actuator becomes farther because of the machine deformation, and the length gauge elongates by $0.6 \mathrm{~mm}$. The deformation error will vary with the machine posture, which cannot be compensated accurately by the trial and error method without the use of the outer-loop position compensation.

The position curve of riveting die after compensation of pressing foot position is shown as the lower chart in Figure 14. The length gauge signal is introduced into the position closed loop as the compensation after the insertion action. The actual position of the riveting die can be adjusted according to the real-time feedback of the length gauge, and the length of the length gauge stays at $15 \mathrm{~mm}$ during riveting and dwelling, which proves that the relative position of the riveting die and the pressing foot remains unchanged, so that the rivet manufactured head is not affected by the machine deformation and is always pressed against the countersink hole to eliminate the gapping under the head.

As shown in Figure 15, the mound height is measured using the flatness gauge. Compared with the rivets formed with foot position compensation, the manufactured head using a legacy process has obvious protrusion. The riveting control method proposed in this paper can control the range of the mound height within $0.03 \mathrm{~mm}$ as shown in the upper chart in Figure 16, which indicates that the gapping under the manufactured head is well eliminated and meets the aerodynamic requirement of panels. In contrast, the mound height of rivets formed using a legacy process ranges from 
TABle 4: Experimental results (average data for each posture).

\begin{tabular}{lccccccc}
\hline Items & Posture 1 & Posture 2 & Posture 3 & Posture 4 & Posture 5 & Posture 6 & Posture 7 \\
\hline$S(\mathrm{~mm})$ & 4.14 & 3.89 & 3.75 & 3.71 & 3.73 & 3.81 & 3.86 \\
$F(\mathrm{KN})$ & 18.00 & 18.01 & 18.00 & 17.99 & 18.02 & 18.00 \\
$\delta(\mathrm{mm})$ & 0.31 & 0.26 & 0.21 & 0.18 & 0.23 & 0.35 \\
$H(\mathrm{~mm})$ & 2.03 & 1.99 & 2.01 & 2.08 & 1.94 & 2.00 \\
\hline
\end{tabular}

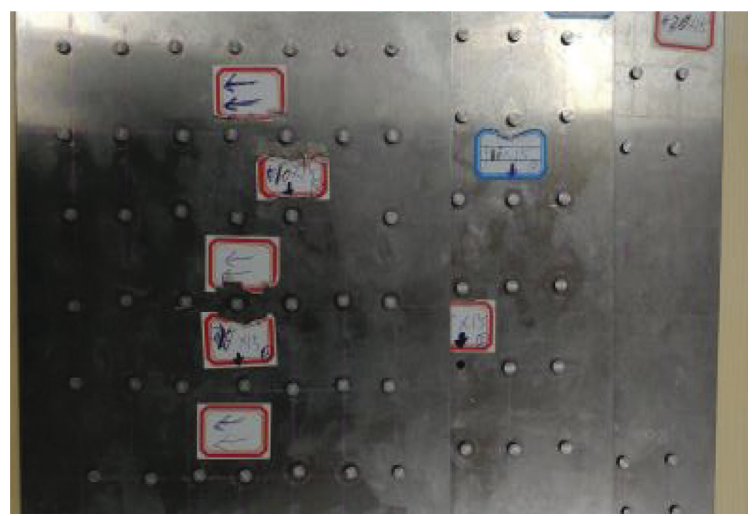

(a)

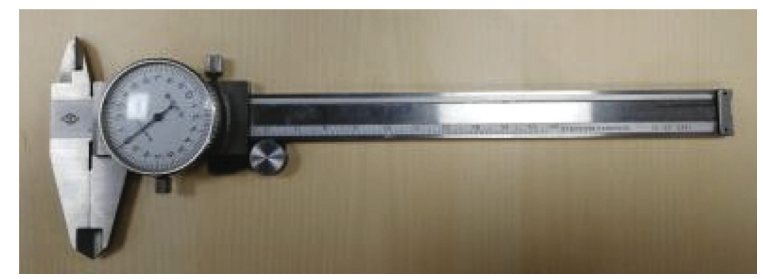

(b)

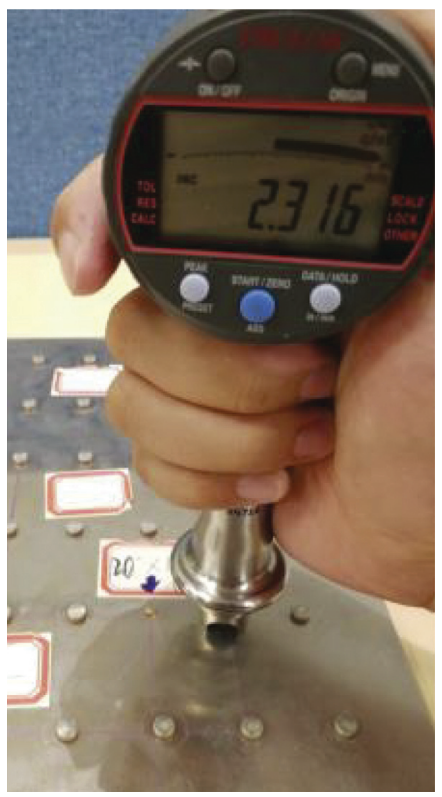

(c)

Figure 21: Measuring the driven head. (a) Riveted joints. (b) Vernier caliper. (c) Digital flushness gage.

$0.03 \mathrm{~mm}$ to $0.12 \mathrm{~mm}$ as shown in the lower chart in Figure 16.

The cross section view of specimens is shown in Figure 17. The gapping under the manufactured head is obvious when the traditional position control without compensation is adopted, which affects the uniformity of interference distribution and airtightness. Using the position control with foot position compensation to suppress the negative effect of machine deformation, the problem of gapping is obviously improved and a good interference between rivet and countersink is obtained.
4.2.2. Performance of the Force Controller. The force control process of the inside riveting die is shown in Figure 18. Under normal forming conditions, the riveting die completes the squeezing rivet following force command and then unloads after dwelling. The riveting die feed in force control model follows the force command, so its actual feed is larger than the force-induced deformation error. This model can ensure the accuracy of rivet driven head by precise force control without obtaining the accurate stiffness model, although the stiffness of machine varies a lot with the posture of machine. 


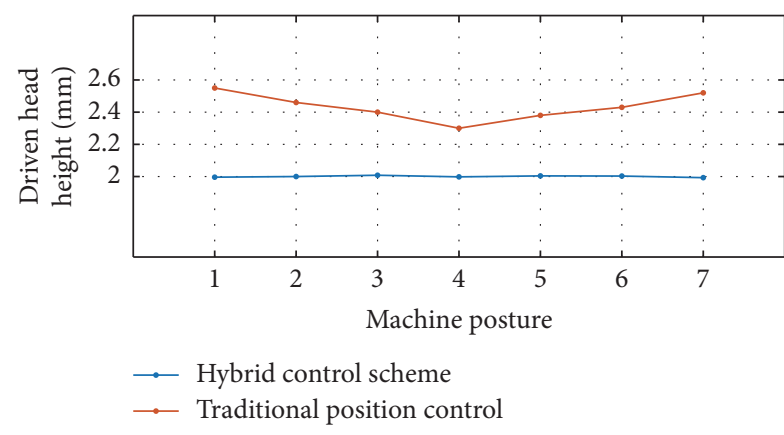

(a)

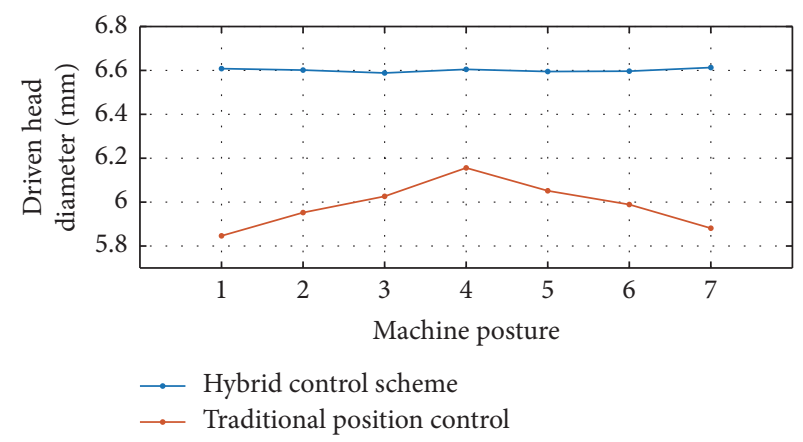

(b)

Figure 22: Comparison of riveted joints with different control scheme.

The experimental results in Figure 19 verify that the force tracking performance is improved by the feedforward controller, and Figure 20 shows that the $\mathrm{DOB}$ can restrain exogenous disturbances effectively and reduce the force tracking error.

4.2.3. Effect of Driven Head Size Control. Experimental results of average data for each posture under the proposed hybrid position/force control are shown in Table 3, where $S$ denotes the feeding distance of the inside riveting die in force control mode, $F$ denotes the riveting force, $\delta$ denotes the compensation amount of the outside riveting die, and $H$ denotes the height of rivet driven head. The completed measurement results are given in Table 3 of the Appendix. From the results listed in Table 4, the height of the driven head can achieve a tolerance of $\pm 0.1 \mathrm{~mm}$ by controlling the riveting force, and the inside riveting die feeding distance is different, which is determined by the stiffness of the machine.

By contrast, the experiment under the traditional position riveting control is also carried out. As shown in Figures 21 and 22, the consistency of the driven head size under traditional position control without compensation is very poor compared with the proposed hybrid control scheme.

\section{Conclusion}

In this paper, the hybrid position/force riveting control method for dual-machine riveting system is proposed to compensate the machine deformation. The hybrid control strategy based on position control with pressing foot compensation and DOB-based force control is adopted for riveting actuator on both sides. The experimental results show that this method can realize high-quality riveting without accurate machine stiffness model. The height tolerance of rivet driven head is $\pm 0.1 \mathrm{~mm}$, and the gapping under the manufactured head can be prevented. The contributions of this paper are listed as follows:

(1) The hybrid position/force control strategy is proposed for the dual-machine riveting system to compensate the machine deformation. This method can be applied to the riveting system whose stiffness varies with posture in a wide range in the machining space, and the high precision riveting can be realized without obtaining accurate stiffness model.

(2) The position control based on pressing foot position compensation ensures the position of the manufactured head relative to the countersink unchanged, which eliminates the gapping under the manufactured head and realizes the interference connection between the rivet head and the countersink.

(3) The flexible riveting axis dynamics model is established for the force controller design, and the modelbased DOB and feedforward control strategy is adopted to deal with the influence of machine stiffness change on force control. The high robustness and tracking performance of force control loop are achieved by these advanced control algorithms. The height tolerance of rivet driven head is $\pm 0.1 \mathrm{~mm}$ under force control mode.

(4) The experiment carried on the dual-machine riveting system shows that this proposed new method has been effective in the elimination of gapping under the rivet manufactured head and improved consistency of rivet driven head.

Furthermore, not only is the proposed method used in the dual-machine riveting system, but also it has a wide application for the traditional riveting machines or the robot cooperative riveting systems with poor stiffness.

\section{Data Availability}

The data used to support the findings of this study are included within the article.

\section{Conflicts of Interest}

The authors declare that there are no conflicts of interest regarding the publication of this paper.

\section{Acknowledgments}

This work was supported by the National Natural Science Foundation of China (Grant nos. 51975519 and 51775495). 


\section{References}

[1] A. Skorupa and M. Skorupa, Riveted Lap Joints in Aircraft Fuselage: Design, Analysis and Properties, Spring Verlag, Dordrecht, The Netherlands, 2012.

[2] E. C. Stansbury, B. Bigoney, and R. Allen, "E7000 high-speed CNC fuselage riveting cell," SAE International Journal of Materials and Manufacturing, vol. 7, no. 1, pp. 37-44, 2013.

[3] T. Rummell, "The evolution of all electric fastening systems: G86 to multi-flex," SAE International Journal of Materials and Manufacturing, vol. 3016, p. 6, 2000.

[4] T. Dillhöfer and B. Bankston, "Mpac (multi panel assembly cell)," SAE International Journal of Materials and Manufacturing, vol. 3091, p. 11, 2009.

[5] G. Li, G. Shi, and N. C. Bellinger, "Stress in triple-row riveted lap joints under the influence of specific factors," Journal of Aircraft, vol. 48, no. 2, pp. 527-539, 2011.

[6] J. Derijck, J. Homan, J. Schijve, and R. Benedictus, “The driven rivet head dimensions as an indication of the fatigue performance of aircraft lap joints," International Journal of $\mathrm{Fa}$ tigue, vol. 29, no. 12, pp. 2208-2218, 2007.

[7] M. Skorupa, A. Skorupa, T. Machniewicz, and A. Korbel, "Effect of production variables on the fatigue behaviour of riveted lap joints," International Journal of Fatigue, vol. 32, no. 7, pp. 996-1003, 2010.

[8] Z. Zhang, Z. Liu, Q. Cheng, Y. Qi, and L. Cai, “An approach of comprehensive error modeling and accuracy allocation for the improvement of reliability and optimization of cost of a multiaxis NC machine tool," The International Journal of Advanced Manufacturing Technology, vol. 89, no. 1-4, pp. 561-579, 2017.

[9] K.-C. Wang, "Optimal high-rigidity structure design for CNC machine tools using CAE technique," Engineering Computations, vol. 31, no. 8, pp. 1761-1777, 2014.

[10] D. T.-Y. Huang and J.-J. Lee, "On obtaining machine tool stiffness by CAE techniques," International Journal of Machine Tools and Manufacture, vol. 41, no. 8, pp. 1149-1163, 2001.

[11] M. Smaoui, Z. Bouaziz, A. Zghal, G. Dessein, and M. Baili, "Simulation of the deflected cutting tool trajectory in complex surface milling," The International Journal of Advanced Manufacturing Technology, vol. 56, no. 5-8, pp. 463-474, 2011.

[12] Z. Peter, F. John, and E. Osman, "Riveting thin A320 stacks," SAE International Journal of Materials and Manufacturing, vol. 2264, 2014.

[13] J. Liu, Z. Zhao, Y. Bi, and H. Dong, "Prediction and compensation of force-induced deformation for a dual-machinebased riveting system using FEM and neural network," The International Journal of Advanced Manufacturing Technology, vol. 103, no. 9-12, pp. 3853-3870, 2019.

[14] Y. Zhang, Q. Bi, L. Yu, and Y. Wang, "Online compensation of force-induced deformation for high-precision riveting machine based on force-displacement data analysis," The International Journal of Advanced Manufacturing Technology, vol. 94, no. 1-4, pp. 941-956, 2018.

[15] J. Duan, Y. Gan, M. Chen, and X. Dai, “Adaptive variable impedance control for dynamic contact force tracking in uncertain environment," Robotics and Autonomous Systems, vol. 102, pp. 54-65, 2018.

[16] J. Peng, Z. Yang, and T. Ma, "Position/force tracking impedance control for robotic systems with uncertainties based on adaptive jacobian and neural network," Complexity, vol. 2019, Article ID 1406534, 16 pages, 2019.
[17] T. Zhang and X. Liang, "Disturbance observer-based robot end constant contact force-tracking control," Complexity, vol. 2019, Article ID 5802453, 20 pages, 2019.

[18] Y. Gan, J. Duan, M. Chen, and X. Dai, "Multi-robot trajectory planning and position/force coordination control in complex welding tasks," Applied Scieces, vol. 9, no. 5, p. 924, 2019.

[19] Q. Liu, Q. Jin, and B. Huang, "Iteration tuning of disturbance observer-based control system satisfying robustness index for FOPTD processes," IEEE Transactions on Control Systems Technology, vol. 25, no. 6, pp. 1978-1988, 2016.

[20] J. N. Yun and J. B. Su, "Design of a disturbance observer for a two-link manipulator with flexible joints," IEEE Transactions on Control Systems Technology, vol. 22, no. 2, pp. 809-815, 2013.

[21] L. Wang, J. Su, and G. Xiang, "Robust motion control system design with scheduled disturbance observer," IEEE Transactions on Industrial Electronics, vol. 63, no. 10, pp. 6519-6529, 2016.

[22] S. Oh and K. Kong, "High-precision robust force control of a series elastic actuator," IEEE/ASME Transactions on Mechatronics, vol. 22, no. 1, pp. 71-80, 2016.

[23] D. Zhao, Y. Bi, and Y. Ke, "An efficient error compensation method for coordinated CNC five-axis machine tools," International Journal of Machine Tools and Manufacture, vol. 123, pp. 105-115, 2017.

[24] D. Zhao, Y. B. Bi, and Y. L. Ke, "A united kinematic calibration method for a dual-machine system," Assembly Automation, vol. 38, no. 2, pp. 226-238, 2017.

[25] Y. Liu, Q. Fang, A. Zhao, F. Yang, H. Wang, and Y. Ke, "Design of DOB-based riveting force controller for dualmachine horizontal drilling and riveting system," Mechatronics, vol. 63, Article ID 102263, 2019.

[26] G. Alici and B. Shirinzadeh, "Enhanced stiffness modeling, identification and characterization for robot manipulators," IEEE Transactions on Robotics, vol. 21, no. 4, pp. 554-564, 2005.

[27] Y. Guo, H. Dong, and Y. Ke, "Stiffness-oriented posture optimization in robotic machining applications," Robotics and Computer-Integrated Manufacturing, vol. 35, pp. 69-76, 2015.

[28] L. Reithmaier and R. Sterkenburg, Standard Aircraft Handbook for Mechanics and Technicians, McGraw-Hill, New York, NY, USA, 2014. 